\title{
Memories of vacant lots: How and why residents used informal urban greenspace as children and teenagers in Brisbane, Australia and Sapporo, Japan
}

Authors' accepted manuscript (April 2015), self-formatted for increased legibility ${ }^{1}$.

Journal: Children's Geographies. Version of record: 10.1080/14733285.2015.1048427

Christoph D. D. Rupprecht

Environmental Futures Research Institute, Griffith University, Nathan, Australia

Griffith School of Environment, Griffith University, Gold Coast, Australia

Email: $\quad$ christoph.rupprecht@griffithuni.edu.au

Jason A. Byrne

Email: $\quad$ jason.byrne@griffith.edu.au

Environmental Futures Research Institute, Griffith University, Nathan, Australia

Griffith School of Environment, Griffith University, Gold Coast, Australia

Alex Y. Lo

Email: $\quad$ alexloyh@hku.hk

The Kadoorie Institute, University of Hong Kong, Hong Kong

This work was supported by the Japan Society for the Promotion of Science under Grant number [24658023], and by Griffith University in the form of doctoral research project funding.

\begin{abstract}
Contact with nature is vital for the development of children and teenagers. In the past, informal urban greenspaces (IGS) such as vacant lots appear to have been used for such purposes. We need to better understand how previous generations used IGS to make sure young people today can also enjoy its social, mental, emotional and physical health benefits. This study quantitatively compared adult residents' memories of IGS use in their childhood and teen age years in two geographically and culturally distinct cities: Brisbane, Australia and Sapporo, Japan. The results showed most respondents $(>70 \%)$ remembered using IGS in the past, and preferred it over other greenspace because it was easily accessible. Most $(>70 \%)$ recalled experiencing no problems (e.g. danger of injury) when using IGS, a contrast to recently increasing parental concern for children's
\end{abstract}

\footnotetext{
${ }^{1}$ Changes: Inclusion of supplementary figures in text, renumbered figures.
} 
safety. Such factors may limit present IGS use and prevent it from fulfilling the important role it played for previous generations' recreation.

\section{Introduction}

\footnotetext{
"When I was a child, there were lots of vacant lots and it was normal for kids to play there. Today most of them are hard to get into." (Hiroko, 52, female, from Sapporo)
}

There is a growing consensus that young people need contact with the natural environment (Cheng and Monroe 2012; Moore, 1997). It can offer children and teenagers opportunities for unstructured play, making sense of the world around them, encountering animals and plants, collecting items, and provides space for social interactions as well as time spent alone (Henniger 1994; Bell, Ward Thompson, and Travlou 2003; Lekies and Beery 2013; Ward Thompson 2002). Such activities play an important role for children's social, mental, emotional and physical health and development (Maller 2009; Keniger et al. 2013; Wolch et al. 2011). However, children's outdoor play time may be declining, driven by changing play preferences such as an increase in television time and concerns about crime and safety (Clements 2004; Fukuya 1999), which could cause children to miss out on the benefits associated with nature contact.

In urban areas, formal greenspace (e.g. parklands, recreation and conservation areas) is assumed to provide opportunities for nature contact (Brisbane City Council, 2010; Hartig et al. 2014; Sapporo Kankyōkyoku Midori No Suishinbu 2011). Although parks are valued for the opportunities they offer, researchers have suggested they may fail to satisfy young people's needs (Ward Thompson 2012; Platt 2012). Many parks are governed by strict rules limiting how they may be used (Gaster 1991). Park design usually circumscribes the experiences available (e.g. types of animals and plants present), and rarely allows users to modify the space (e.g. by building structures or storing items). In Japan, even popular activities such as ball games are often forbidden in parks (Figure 1). 


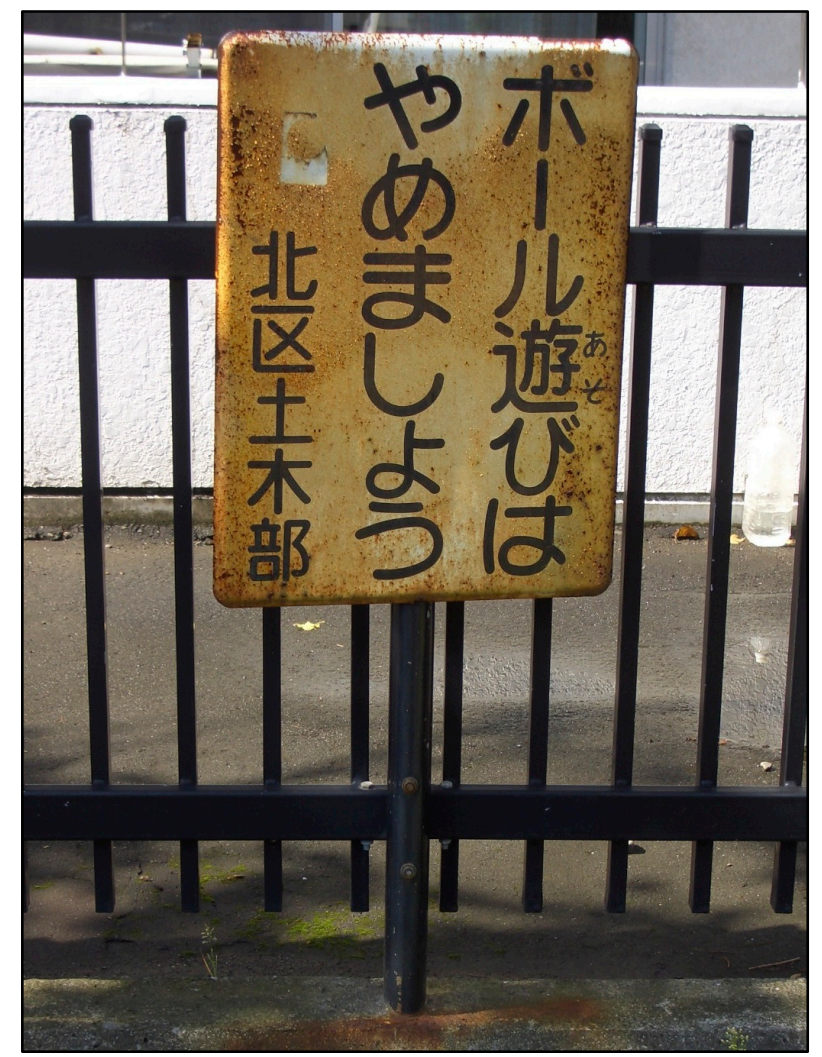

Figure 1 Sign restricting ball play in public greenspace (Sapporo, Japan). Translation of sign: "Let's refrain from ball play. -Kita Ward Civil Engineering Department"

To circumvent these restrictions, young people may seek out less controlled spaces, (e.g. vacant lots, river banks and other 'informal greenspaces' (IGS). Freedom from purpose makes these spaces malleable (Cloke and Jones 2005). Children and teenagers value such spaces (Berg and Medrich 1980; Elsley 2004; Mugford 2012; Schneekloth 2007). Scholars argue these spaces can offer excitement, provide opportunities for exploration, escape from adult supervision, and a sense of ownership (Carr and Lynch 1968; Donnelly 1980; Nohl 1990). But children and teenagers today seem less free in choosing how and where to spend their time; their contact with nature, and especially their use of IGS may be limited by increased parental concern for safety (Valentine and McKendrick 1997). Vacant lots are less commonly available, and are increasingly hard to access (Hayashi, Tashiro, and Kinoshita 1999). This begs the question: how widely did previous generations use IGS as children and teenagers? To what degree are young people today deprived of using greenspace types they have been taught to avoid - what Louv calls a 'nature deficit syndrome' (2008)? Five important 
gaps in our knowledge of past use of IGS need to be addressed if we wish to better understand how young people today may have reduced nature contact.

Firstly, most previous work on children and teenager's play in IGS provides few quantifiable details. What proportion of young people used informal greenspaces, and how often did they use it? While scholars have reported a wide variety of play activities (Cloke and Jones 2005; Platt 2012; Pyle 2002; Berg and Medrich 1980; Moore 1986; Ward 1978), it is unclear which are the most common (e.g. observing organisms, hiding from adults).

Secondly, the literature suggests IGS was used to avoid restrictions encountered elsewhere (e.g. park rules, adult supervision) and fostered spending private time (Ward Thompson 2012; Louv 2008). But previous work makes it difficult to weigh how important the various reasons are. Given that children today are reportedly less free to roam, how did previous generations value proximity of IGS? Were they less constrained than children today?

Thirdly, the literature says little about the problems children and teenagers in the past had with using IGS. How risky or dangerous did they perceive it to be? Did their parents forbid them from visiting such spaces? Did they encounter dangerous animals or plants? Were there conflicts with the IGS' owner/manager, the police, or other users? Decades ago, efforts were already in place to regulate children's play environments (Read 2010; Los Angeles Department of Playground and Recreation 1938).

Fourthly, the current literature on gender differences in IGS use is scarce. Are there any differences between their IGS use or use frequency? Do girls and boys use IGS for the same activities and reasons? Are they experiencing the same problems? Answering these questions could indicate if there are gender-specific barriers to IGS use similar to those in public spaces (van der Burgt 2013).

Finally, much of the prominent literature on young people's use of IGS is published in English and reports results from Europe and the United States (Rupprecht and Byrne 2014a - see chapter 2; Jorgensen and Keenan 2012). Recent results showed residents in a Japanese city appreciated and used IGS significantly less than those in an Australian city (Rupprecht et al., forthcoming - see chapter 4). Rapid urbanization throughout the world (United Nations, Department of Economic and Social Affairs, Population Division 2012) makes it important to learn about local histories of IGS use, as they may indicate what role IGS could play for today's young people, who struggle with limited access to formal greenspace. 
To address these five gaps in the literature, this paper reports the results of a study that asked the following five research questions:

(1) How did adults use IGS in their childhood and teenage years, and what activities did they use IGS for?

(2) Why did they use IGS and not a formal greenspace (e.g. a park or garden)?

(3) What problems did they encounter when using IGS?

(4) How did their IGS use, reasons and problems differ between females and males?

(5) How did their IGS use, reasons and problems differ between geographically and culturally distinct locations?

\section{Methods}

\section{Study area}

Brisbane (Queensland, Australia) and Sapporo (Hokkaidō, Japan) were selected as case study cities. As we have described elsewhere (Rupprecht and Byrne 2014b - see chapter 3), these cities share similarities and differences that lend well to comparison (e.g., similarities in size, morphology, and geography; differences in available greenspace, population density and growth forecasts). In both cities, formal greenspace consists of networks of over 2,000 public parks in both cities, many of them small local parks. Brisbane has 3,290 ha of local parkland (32 $\mathrm{m}^{2} /$ capita), whereas Sapporo has 2,345 ha $\left(12.3 \mathrm{~m}^{2} /\right.$ capita). All parks in Brisbane comprise an area of $11,840 \mathrm{ha}\left(115 \mathrm{~m}^{2} /\right.$ capita $)$, while those in Sapporo combine to form an area of 5,508 ha $\left(28.9 \mathrm{~m}^{2} /\right.$ capita) (Rupprecht and Byrne 2014b).

\section{Working with memories: possibilities and limitations}

Quantitative data (e.g. governmental statistics) is even less available for past IGS play activities (including customs and behaviours) than for present ones. We can, however, ask respondents to remember and report their childhood experience with IGS. Researchers have discussed the complexity of "memory as methodology" (Philo 2003; Jones 2003). Cloke and Jones (2005) also point out a gap between children's real experiences and adult constructions of childhood. When using memory to look at childhood, three points need to be taken into account: our own experience of childhood, nostalgia as a result of an adult desire to reinterpret past experiences, and the different 
vantage point - adulthood - from which researchers approach childhood (Treacher 2000). Nostalgia may pose the biggest problem when examining past play through adult's memories. But prior research suggests adults do not necessarily paint a romanticized picture of their childhood. For example, Valentine and McKendrick (1997) found a majority of their respondents reported they were restricted in their play contrary to the common narrative of past freedom. We thus believe that asking adults to recall their childhood experience with IGS can provide useful and meaningful insights. This approach situates our study in the context of similar on children and teenagers' play experiences (Henniger 1994; Strudler and Schaefer 1997; Ward Thompson, Aspinall, and Montarzino 2007; Jorgensen and Keenan 2012; Karsten 2005; Valentine and McKendrick 1997).

\section{Data collection and analysis}

Data collection was undertaken as part of a larger study on IGS (Rupprecht et al., forthcoming; Rupprecht and Byrne 2014b). A letterbox-drop, reply-paid mail-back questionnaire kit was distributed to a randomized sample of 1,910 households in Brisbane and 1,980 in Sapporo (variation resulted from site accessibility). Households were located within a $400 \mathrm{~m}$ radius (easy walking distance) of 121 sampling sites placed on the intersecting lines of a $10 \mathrm{~km}$ by $10 \mathrm{~km}$ grid, centered on the city centers with a one-kilometer distance between adjacent sites. This allowed coverage of most of the densely populated areas.

The mail-back questionnaire used closed-ended questions with an "other" qualitative, open-ended answer field. Questions asked were part of a larger study on adult residents' perception and evaluation of IGS (Rupprecht et al., forthcoming). The first question in this part of the study asked respondents whether they used IGS as a child or teenager. All follow-up questions regarding use frequency, activities, reasons for using IGS and problems with IGS use were only asked of self-reported child or teenage IGS users. Questionnaire kits included an IGS typology with color photograph examples for every IGS type to minimize the risk of respondents mistaking formal for informal greenspace. All material was initially written in English, translated into Japanese and edited by native speakers. The instrument was approved by the home institution's human subjects research ethics committee (ENV/28/12/HREC) and both versions were pilot tested. 
Data was analysed in SPSS (v. 21 and 22, OS X) to perform descriptive and inferential statistical tests. As the sample data was not normally distributed, nonparametric tests (Mann-Whitney U, Fisher's exact) were used to determine whether answers differed significantly $(\mathrm{p}<.05)$ between the two respondent groups (Field 2009).

Finally, open-ended comments provided by the respondents in the instrument section on IGS appreciation were qualitatively analysed using coding and content analysis to identify key concepts (Sproule 2006). In the first round, all comments were screened and categorized based on their main topic with implicit coding (Sproule 2006). We then selected the comments from the category 'young people and IGS' and identified key concepts (e.g. "play", "problems") based on a conceptual content analysis approach (Sproule 2006). Based on these key concepts, the comments were drawn upon to provide a qualitative context in discussing the quantitative results of the survey. Respondents were assigned pseudonyms chosen from popular names during their time of birth in their respective cultures to protect their anonymity.

\section{Results}

The number of valid responses in Brisbane was 123 and 163 in Sapporo. To compare only Australian and Japanese experiences, we excluded responses from residents born in other countries from the analysis (Brisbane $n=22$, Sapporo $n=0$ ). Respondents in Brisbane were 59.4\% female (median age 51, age range 19-84), respondents in Sapporo $53.2 \%$ female (median age 58, age range 21-90).

\section{Memories of IGS use and activities}

In Brisbane, $85.1 \%$ of respondents recalled using IGS as a child or teenager, in comparison to $72.4 \%$ in Sapporo. Among those who reported using IGS as children or teenagers, daily users comprised the largest group in Sapporo, while weekly users comprised the largest group in Brisbane (Figure 2). Among those who reported using IGS as children or teenagers, weekly users still comprised the largest group in Brisbane, while in Sapporo the largest group were those who never used IGS (Figure 3). 


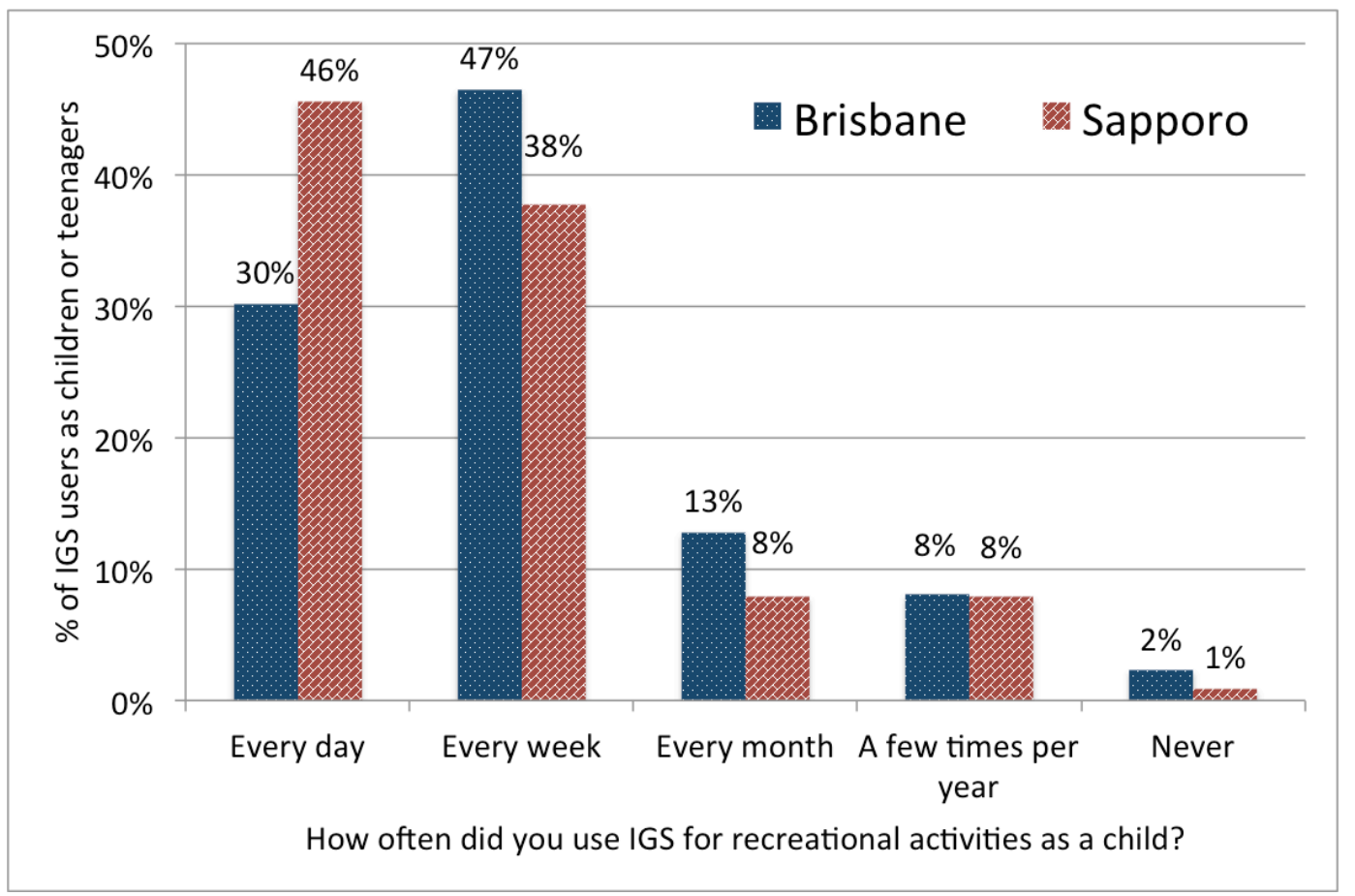

Figure 2 Frequency of IGS use during childhood.

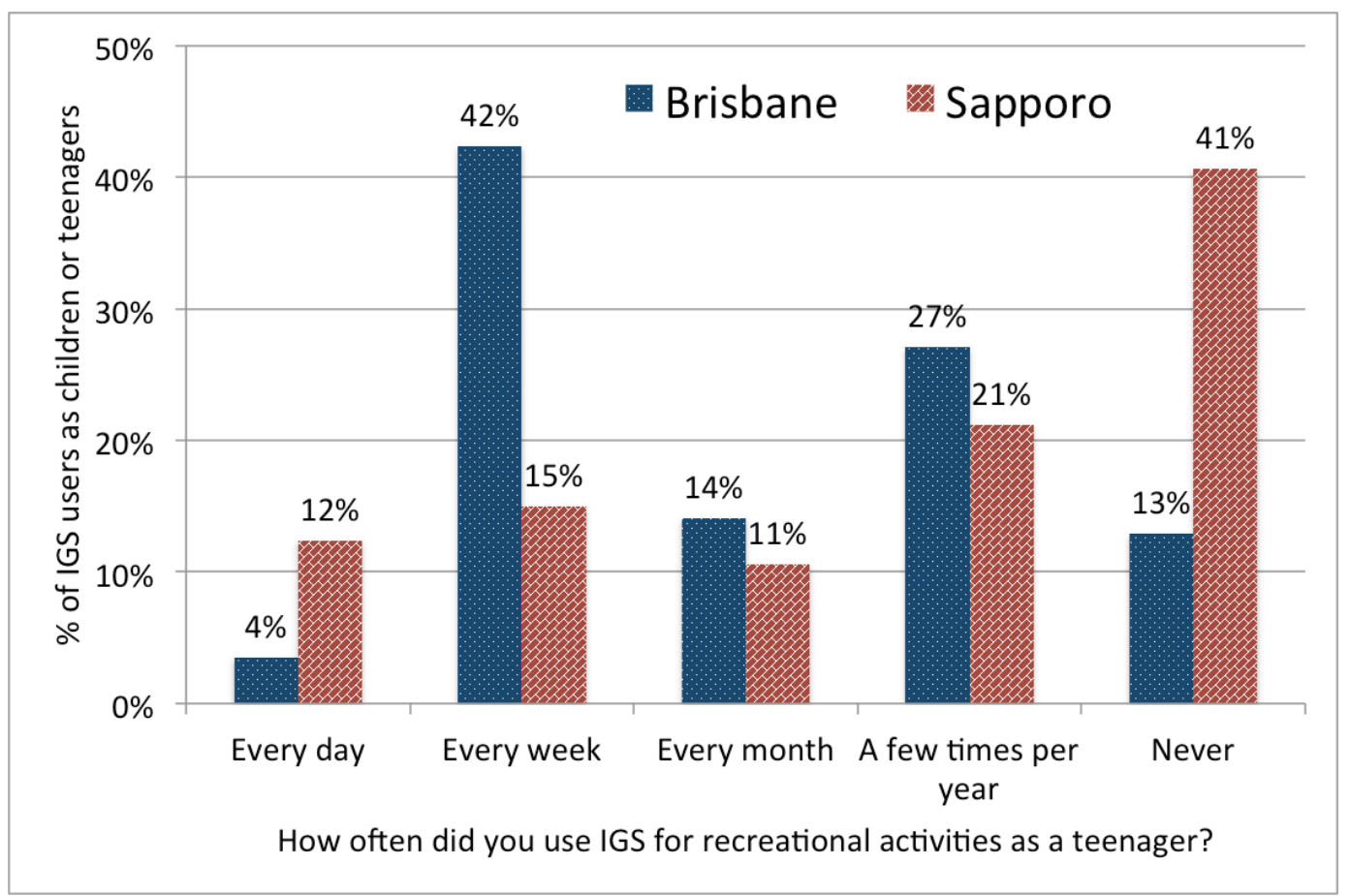

Figure 3 Frequency of IGS use during adolescence. 
When using IGS as children, the most common activities Brisbane respondents reported were exploration, playing games, and seeking a private place secret from adults (Table 1). As "other activities" they mentioned BMX tracks, riding bikes, horse riding, hunting, taking short cuts, swimming, thinking, and tree-climbing. Sapporo respondents' most commonly reported activities as children were playing games, exploration, and observing wildlife or plants (Table 1, Figure 4). As "other activities" they mentioned tennis, badminton, side trips with friends on the way home from school, taking shortcuts, commuting to school, gathering bamboo, and fishing.

Table 5.1 Recreational activities in IGS during childhood and adolescence.

\begin{tabular}{|c|c|c|c|}
\hline Question asked & Response options & Brisbane & Sapporo \\
\hline & & $\%$ & $\%$ \\
\hline \multirow{4}{*}{$\begin{array}{l}\text { What kind of } \\
\text { activities did you } \\
\text { use IGS for as a } \\
\text { child? }\end{array}$} & Playing games & 84.5 & 97.3 \\
\hline & Walks & 57.1 & 12.6 \\
\hline & Exploration & 90.5 & 61.3 \\
\hline & Private place secret from adults & 58.3 & 36.9 \\
\hline \multirow{12}{*}{$\begin{array}{l}\text { What kind of } \\
\text { activities did you } \\
\text { use IGS for as a } \\
\text { teenager? }\end{array}$} & Building hut or tree-house & 47.6 & 8.1 \\
\hline & Treasure-hunting (looking for items) & 33.3 & 24.3 \\
\hline & Observing wildlife or plants & 41.7 & 40.5 \\
\hline & Other & 15.5 & 7.2 \\
\hline & Playing games & 29.3 & 75.7 \\
\hline & Walks & 69.3 & 31.4 \\
\hline & Exploration & 48.0 & 15.7 \\
\hline & Private place secret from adults & 42.7 & 10.0 \\
\hline & Building hut or tree-house & 8.0 & 2.9 \\
\hline & Treasure-hunting (looking for items) & 5.3 & 5.7 \\
\hline & Observing wildlife or plants & 26.7 & 30.0 \\
\hline & Other & 20.0 & 10.0 \\
\hline
\end{tabular}

When using IGS as teenagers, the most common activities Brisbane respondents recalled were walking, exploration, and seeking seclusion from adults (Table 1). As "other activities" they mentioned contemplation, horse riding, bike riding, hunting, jogging, photography, relaxing, taking short cuts, swimming, and thinking in solitude. Sapporo respondents' most commonly reported activities as teenagers were playing games, walking, and observing wildlife or plants (Table 1). As "other activities" they mentioned relaxing when tired from school, walking the dog, taking short cuts, and commuting to school. 


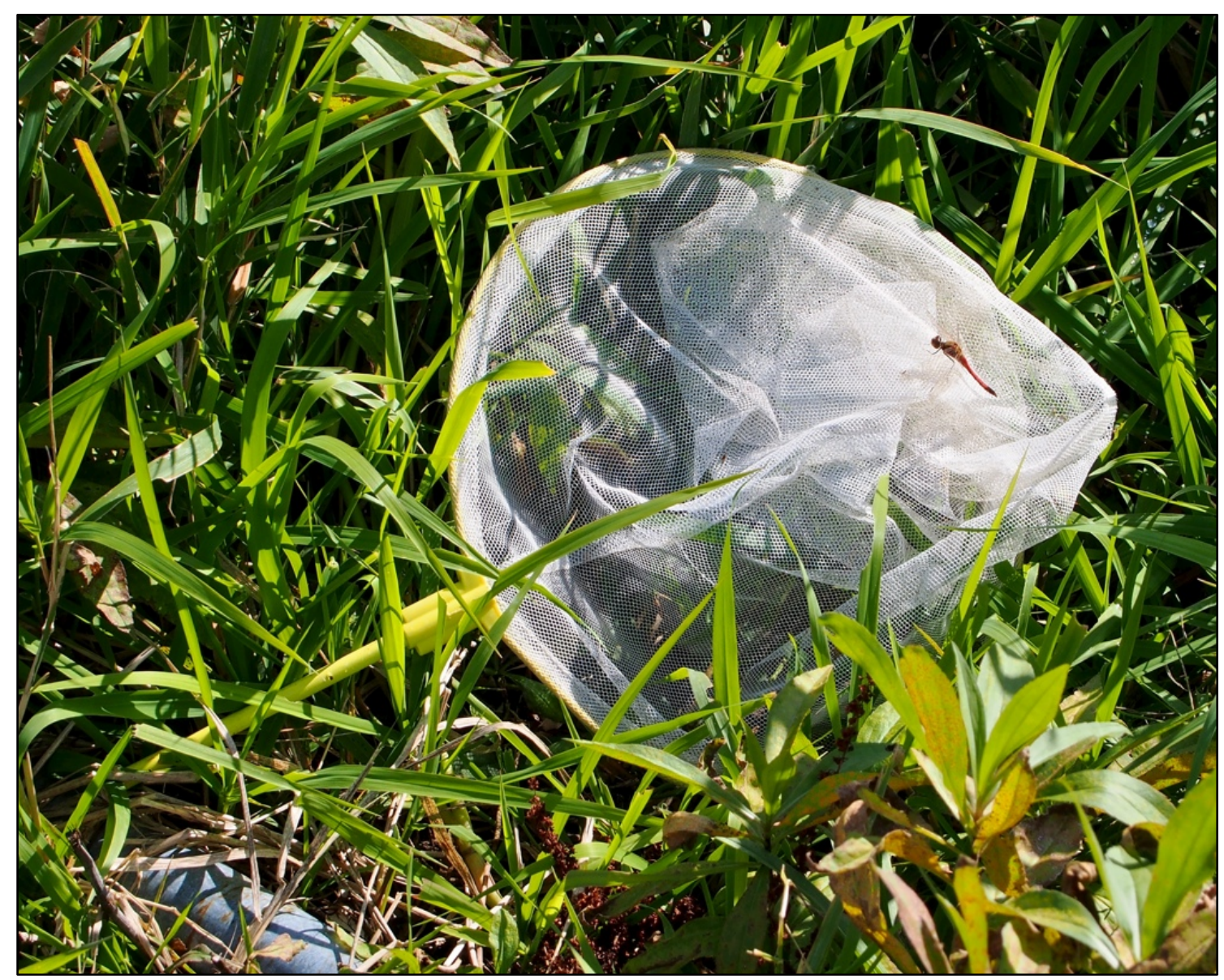

Figure 4 Butterfly net such as commonly used by children to catch insects, found in Sapporo IGS.

\section{Remembering reasons for preferring IGS}

Respondents reported various reasons for using IGS instead of a park or garden. Brisbane respondents recalled most commonly choosing IGS for its ease of access, because they perceived it as wild and exciting, and valued solitude (Table 2). As "other reasons" they mentioned it provided opportunities for unrestricted use, swimming, and modifying the environment, and also mentioned it contained elements that made it more interesting than formal greenspace (e.g., mounds of dirt, concrete pipes, thickets of bush).

Sapporo respondents recalled most commonly choosing IGS for its ease of access, because they felt they lacked pleasant parks near their homes, the lack of use restrictions, and because they perceived it as wild and exciting (Table 2). As "other reasons" they mentioned it provided space for solitary contemplation, space to chat with friends away from parks occupied by children and their parents, opportunities to ski in winter. One mentioned IGS contained 'a shack that was used as a secret base'. 
Table 5.2 Respondents' reasons for using IGS

\begin{tabular}{llll} 
Question asked & Response options & Brisbane & Sapporo \\
\hline & & $\%$ & $\%$ \\
Why did you use & It's near my home & 75.6 & 81.0 \\
informal & It's wild and exciting & 53.7 & 30.5 \\
greenspace and & It's not crowded & 42.7 & 13.3 \\
not a park or & There are more or different animals or plants & 20.7 & 17.1 \\
garden (as a & It has better privacy (nobody watching) & 39.0 & 10.5 \\
child or & There are no use restrictions (e.g., no dogs, & & \\
teenager)? & no ball play) & 35.4 & 30.5 \\
& It can be used for many things (e.g., & 12.2 & 3.8 \\
& gardening) & 13.4 & 31.4 \\
& There are no nice parks near my home & 7.6 & 7.6 \\
& I don't have a garden or similar greenspace & 4.9 & 11.0 \\
& Other & & 5.7
\end{tabular}

\section{Recalling problems using IGS}

Remembering their childhood experience, no problems were reported with using IGS by $77.1 \%$ of users in Brisbane and $77.5 \%$ of users in Sapporo. Brisbane respondents reported the most common problems experienced as children using IGS were danger of injury, lack of parental permission to use IGS, dangerous animals and litter (Table 3). As "other problems", respondents mentioned they were unsure of the legality of using the space. Sapporo respondents' most commonly experienced problems when using IGS as children were danger of injury, litter, and difficult access (Table 3). As "other problems" they mentioned hygiene concerns due to the presence of animal carcasses, and also mentioned that homeless people lived there occasionally.

Remembering their teenager experience, no problems were reported with using IGS by $74.3 \%$ of users in Brisbane and $81.7 \%$ in Sapporo. Brisbane respondents reported the most common problems experienced as teenagers with using IGS by Brisbane respondents were danger of injury, conflict with other users and difficult access (Table 3). As “other problems", respondents mentioned, as with childhood use, they were unsure of the legality of using the space. Sapporo respondents' most common problems when using IGS as teenagers were danger of injury and "other problems", such as the presence of bears or homeless people. 
Table 5.3 Problems experienced while using IGS during childhood and adolescence

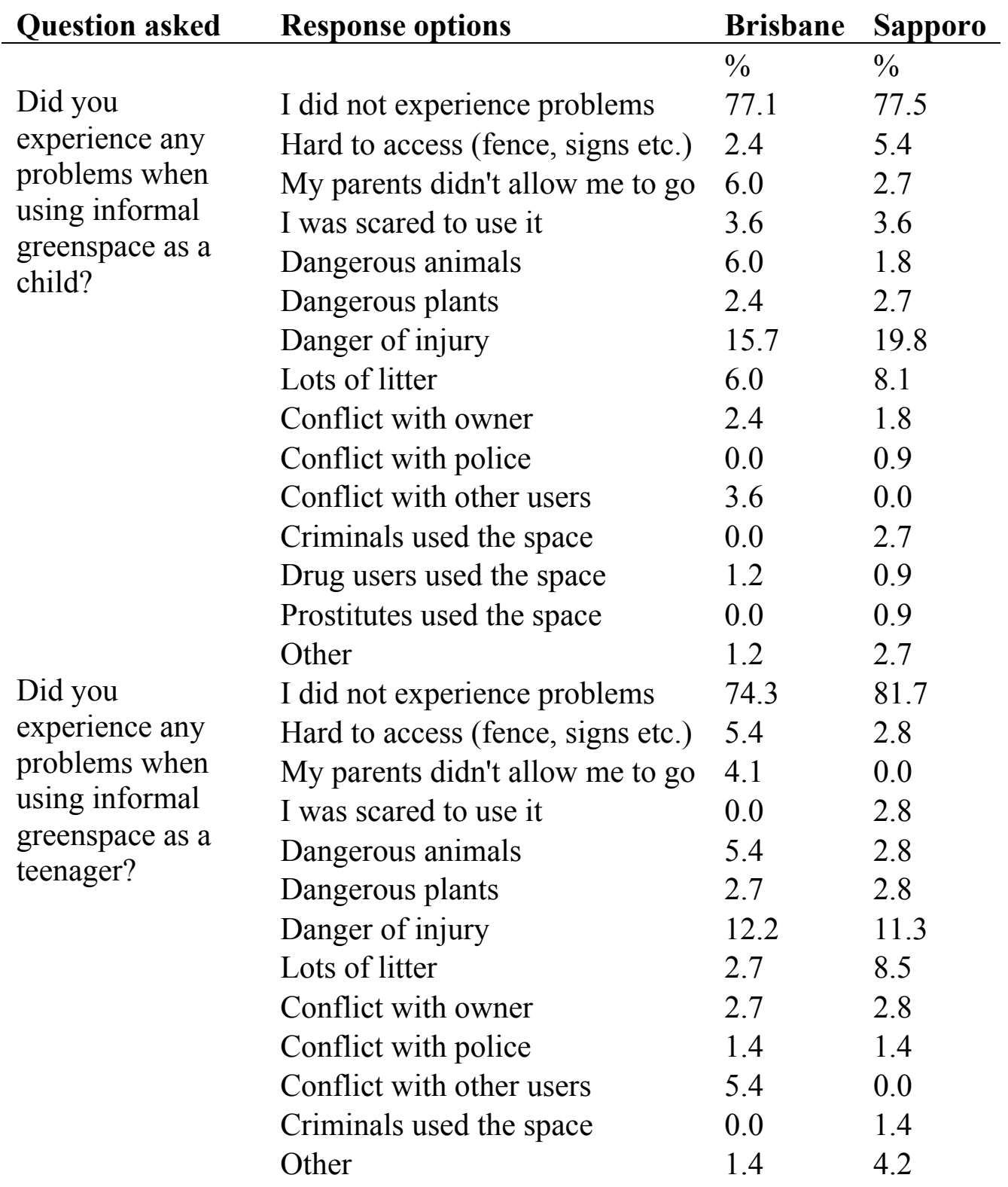

\section{Gender differences}

Comparing female and male respondents in Sapporo, neither the total proportion of respondents who recalled using IGS either as children or teenagers, nor the remembered frequency of IGS use as children was significantly different. However, female IGS users reported visiting IGS significantly less frequently as teenagers $(n=109, p=.009$, $\mathrm{U}=1070.0, \mathrm{z}=-2.398, \mathrm{r}=-.249)$. As teenagers, male IGS users were more likely to report using IGS for playing games $(n=114, p=.005$, odds ratio 3.10), and for observing animals or plants $(\mathrm{n}=114, \mathrm{p}=.006$, odds ratio 4.62), were more likely to report experiencing no problems $(\mathrm{n}=114, \mathrm{p}=.024$, odds ratio 2.76$)$, and to recall using IGS 
because it had more or different animals or plants $(n=114, p=.019$, odds ratio 3.80). There were no significant differences between female and male respondents' memories of IGS activities or problems experienced as children. Comparing female and male respondents in Brisbane, the only significant difference found was that male respondents who recalled using IGS as children were more likely to report using IGS for walking $(\mathrm{n}=83, \mathrm{p}=.021$, odds ratio 3.32$)$.

\section{Differences between study cases}

Comparing the two study cases, the number of respondents who remembered using IGS as a child or teenager was only moderately higher in Brisbane ( $<<0.05$, odds ratio 2.19). Sapporo residents recalled using IGS more frequently as children (Figure 1; n=200, $\mathrm{p}=.035, \mathrm{U}=4107.0, \mathrm{z}=-2.106, \mathrm{r}=-.149)$. In contrast, Brisbane residents recalled using it more frequently as teenagers (Figure $1 ; \mathrm{n}=198, \mathrm{p}<.001, \mathrm{U}=3530.0, \mathrm{z}=-3.286, \mathrm{r}=-.234$ ). While only $12.9 \%$ of IGS users in Brisbane reported they never used it as teenagers, the number in Sapporo (40.7\%) was much higher. Regarding respondents' childhood memories, the IGS activities that differed the most between the two cities were walking, building structures, and exploration (Table 1). Regarding respondents' memories of teenage years, the IGS activities that differed the most were playing games, exploration, and using IGS as a private place secret from adults (Table 1). Only in Sapporo did respondents repeatedly mention IGS in connection with commuting to school.

Reported reasons for using IGS and not a park or garden were similar between the two cities for the most important reason (proximity), while the memories differed most for crowding, privacy, and about whether IGS was wild and exciting (Table 2). Problems experienced while using IGS were very similar in both cities. Differences between female and male respondents were more pronounced in Sapporo, but the overall proportion of IGS users and IGS use frequency during childhood were not significantly different between the two case studies. Income and educational background of respondents did not affect recalled IGS use as a child or teenager, and only in Sapporo did respondents' age have a miniscule negative effect ( $\mathrm{p}<0.05$, odds ratio 1.03).

\section{Discussion}

\section{Diverging paths of IGS use: a matter of culture?}

The results of this study generally corroborate what scholars have argued - there appears to be a history of children and teenagers using IGS such as vacant lots and other 
rough, liminal spaces for recreational purposes (Cloke and Jones 2005; Moore 1986; Ward 1978; Mugford 2012). This seems to apply independently of cultural and geographical context for children in this study. The same adults that differed in their appreciation and use of IGS (Rupprecht et al., forthcoming) showed only limited differences in the proportion of respondents who recalled using IGS as children in this study. But in Sapporo, $41 \%$ of those reported they stopped using it as teenagers, while only $13 \%$ did so in Brisbane. Such a decrease in use among teenagers has been previously noted (Bell, Ward Thompson, and Travlou 2003), and may indicate the point of departure that eventually leads to the pronounced difference in adult greenspace use.

What factors could undergird the different ways IGS use has developed in Brisbane and Sapporo according to our respondents' memories? One possible factor could be the large amount of time Japanese junior high and high school students spend participating in schoolwork and school club activities, which may leave them with less time for unstructured play (Nishino and Larson 2003; Larson and Verma 1999). Another possible factor may be differences in IGS characteristics between the two cities, such as a prevalence of street verge IGS type in Brisbane in contrast to lot and gap type IGS in Sapporo, or a more complex vegetation structure in Sapporo IGS (Rupprecht and Byrne 2014b). Finally, research suggests young people's beliefs about nature are influenced by their family and surroundings (Cheng and Monroe 2012). Teenagers in Sapporo may have adopted a more negative image of IGS and used it less, if such a negative image was prevalent in their social environment. This is problematic, because it indicates that social pressure could constrain teenagers' opportunities to engage in activities that some of their peers are using IGS for, even if abandoning IGS as a teenager does not preclude returning to it later in life. A loss of interest might also influence how much teenagers use IGS, as we will discuss in more detail below.

In contrast, a predominantly positive view of IGS for Brisbane adults could possibly account for a comparatively higher reported IGS use by teenagers (Rupprecht et al., forthcoming). But compared to the respondents' appreciation and use of IGS as adults (Rupprecht et al., forthcoming), the differences in proportion of respondents who recalled using IGS as children or teenagers were far less pronounced. This seems consistent with the finding that the problems (or lack thereof) respondents remembered experiencing when using IGS were very similar in both cities. As discussed above, Sapporo respondents reported using IGS less frequently in teenage years, which could indicate that IGS use patterns began to diverge in early adolescence under the influence 
of a teenage social environment. Consequently, the case studies showed the most differences in IGS use as adults (Rupprecht et al., forthcoming).

Comparing the IGS activities that respondents recalled between the two case studies, the observed differences (e.g. in playing games, building tree-houses or seeking privacy) could be explained by a variety of factors. The high percentage for 'playing games' reported by Sapporo respondents may partly be the result of a linguistic peculiarity. Even though 'playing games' is arguably a broad term, the Japanese term 'asobi' (遊び) used in the localized questionnaire may have be interpreted even more broadly. The higher popularity of building huts or tree houses could possibly be explained by cultural differences, as recreational tree house building has been reported to be widely popular in the US, UK and Australian cultures (Pearn 2013). Finally, as discussed above the higher concern that Brisbane respondents showed for crowding could explain why seeking privacy seems to be more important for them.

\section{Losing access or losing interest?}

According to previous research, IGS may offer young people recreational opportunities that formal greenspace might fail to provide (Ward Thompson 2012; Platt 2012). The activities reported by the respondents in this study strengthen these claims. Many of the activities IGS was used for (e.g., privacy from adults or exploration), are only made possible by the absence of rules, safe design and passive surveillance. For example, respondent Haruka (39, female, from Sapporo) emphasized:

\footnotetext{
"Children can experience nature, come in touch with all kind of living things, learn about the preciousness of life. It's also a great chance for them to make up their own games and rules rather than just use the play tools they are given."
}

The reasons respondents recalled for using IGS instead of a park or garden reflect this; they mentioned less crowding, greater wildness, lack of use restrictions and better privacy. Additionally, respondents' most common reason for preferring IGS was its proximity. This provides further evidence of the importance of greenspace within walking distance, as has been previously suggested (Sugiyama and Ward Thompson 2008). These results imply that IGS was widely available to respondents and played an important role for satisfying their need of contact with the natural environment. However, some scholars suggest certain types of IGS such as vacant lots are becoming less common, especially in urban areas with high development and population density 
(Tabata and Kim 1989) - where formal greenspace is already scarce, as respondent Emma (27, female, from Brisbane) pointed out:

\footnotetext{
"As a child I used greenspaces as a playground/exploration ground. I feel they are a great space for children to experience the natural environment, especially in the inner city where this is rarely found."
}

Furthermore, researchers have shown that vacant lots are often made inaccessible, loosing some of their recreational potential (Hayashi, Tashiro, and Kinoshita 1999). This may again constrain children and teenagers' opportunities for unstructured play and contact with the natural environment, putting them at risk of 'nature deficit syndrome' (Louv 2008) as well as health problems such as obesity (Wolch et al. 2011). Such risk may be further exacerbated if they have difficulties accessing IGS.

But if rules and restrictions limit where teenagers in particular can pursue their recreational activities and IGS is offering such space (Ward Thompson 2012), why did respondents' recall using IGS less as they grew older? Cloke and Jones (2005) suggest even young children seek to escape rules and restrictions, and seek to reimagine spaces. Adolescents could be shifting to different leisure and recreational experiences, such as movies, shopping, socializing, or (since the 1980s) video games (Clements 2004; Fukaya 1999). Such changes in behavior could be part of a gradual transition into adulthood and order, away from the disordered and 'unruly' spaces of childhood (Cloke and Jones 2005). Recreational experiences are also known to differ by cultural background (Larson and Verma 1999; Nishino and Larson 2003). Whether decreasing outdoor play opportunities and changing leisure preferences could be linked remains unclear. However, the popularity of video games could signify teenagers' appropriation of cyberspace as new 'unclaimed territory' (Cloke and Jones 2005), a new way to escape adult control and construct identities (Thomas 2007) in ways not afforded by highly ordered and regulated built environments.

\section{'For your own good': children's safety or adults' convenience?}

Most respondents in this study recalled that they experienced no problems when using IGS either as children or teenagers, that very few were not allowed to use it by their parents; less than $20 \%$ experienced any danger of injury. This provides some important context: while Ward (1978) already reported children were severely restricted in their outdoor play and mobility due to parental safety concerns, newer research suggested 
this tendency may be increasing (Valentine and McKendrick 1997; Karsten 2005; Pyle 2002). Respondents could be romanticizing their childhood, yet researchers have shown this is not necessarily the case (Valentine and McKendrick 1997). Could IGS and similar spaces have been safer in the past, or could they have offered greater freedom from regulation, surveillance and order? There is little evidence to support this. Efforts to prevent children playing without supervision in the 'gutter' or street stretch back to the first decades of the 20st century (Read 2010; Los Angeles Department of Playground and Recreation 1938). In Los Angeles for example, supervised play was intended to ward off 'un-Americanism' as well as delinquency and the high cost of corrective institutional measures (Los Angeles Department Playground and Recreation 1938). An unsafe environment was thought to foster juvenile delinquency (Burgess 1916). However, the reason for increased parental restrictions may be found not in a more dangerous environment, but in a shift of parents' attitudes, beliefs and values - a shift to even tighter regulation, surveillance and control (Karsten 2005; Cloke and Jones 2005).

Recent research has shown children and young adults face problems in finding places for free play and unstructured activity (Ward Thompson 2012). Respondent Akiko (42, female, from Sapporo) attests to such problems in Japan:

\footnotetext{
"Today, there's no place for young teenagers to go other than hanging out in front of convenience stores. Even in Doraemon* the children play in vacant lots every day. And parks are so overmaintained there's nothing except a few ants." (*a famous Japanese cartoon series, Authors' note)
}

Scholars argue this problem highlights the underlying conflict between children's need for experiencing adventure and risk, and the trend of constant adult supervision and a low-risk parenting paradigm that denies children such experience (Gaster 1991; Pyle 2002; Cloke and Jones 2005). Mugford (2012, 94) notes such conflict is reflected in IGS-related child literature, where "the role of 'parent' constitutes a barrier to children's access to challenging places and experiences". She questions whether this is always done for the good of the child, asking "how many of the barriers to children's adventurous play are not for the protection of children and based around genuine health and safety concerns, but are purely for adult convenience" (Mugford 2012, 92). Pyle (2002) also reports that even parents who used IGS in their youth may deny their children the same opportunity. But some researchers have argued 
that the dangers and risks found in IGS may contribute to their attractiveness, and may provide opportunities valuable for young people's development (Ward Thompson 2012; Edensor et al. 2012; Nohl 1990). This study's results support these arguments, because they suggest respondents in both cities understood the danger but were not scared of using IGS. The topic of children's access to informal nature warrants further research because, as respondent Thomas (41, male, from Brisbane) argues, such IGS-related aspects of the human-nature relationship may have wide-ranging implications:

"I think that there is a clear link between growing up in an area where children can

"interact" with their environment, and environmental awareness/compassion as an adult. I have travelled extensively and I have seen areas where children grow up in high rise apartments, with only infrequent access to a sterile (i.e., unchanging) park, and these have been the areas of the most unnecessary (and widespread) environmental damage."

Does the fascination of IGS for young people lie in its natural features or in the weakened influence of adult order and power? Cloke and Jones (2005) argue childhood should be conceptualized in terms of otherness, rather than innocence, and disordered spaces represent territories of becoming-other. The seminal works by Ward (1978) and Moore (1986) provide considerable evidence for this - photographs document children's informal play and 'turf maps', visualizing their understanding of landscape. As Cloke and Jones (2005, 321-322) observe, Moore (1986) 'focuses heavily on the importance of "rough ground" and "abandoned places" as potential sites of childhood becoming'. Is the 'green' in IGS thus important, or even necessary? We propose that the spontaneous vegetation characterizing IGS provides a crucial link to the otherness of childhood. The plants that grow in IGS are often invasive weeds, thriving in a harsh urban environment (Del Tredici 2010) - species whose 'otherness qualities need to be offset' by beneficial effects before their existence is tolerated (Gobster 2012, 47). Overgrown fences, out of control grasses, and unstoppable creepers are visual cues for the liminal, informal and derelict that makes IGS attractive (Rupprecht et al., forthcoming; Cloke and Jones 2005).

\section{Playing with bugs: not just for boys}

Only Sapporo respondents showed significant gender differences. Similar differences have been reported in the literature before, such as girls spending more time reading 
while boys are spending more time playing games (Nishino and Larson 2003). While previous research portrayed playing with insects as an activity younger boys usually engage in (Laurent 2005), this study found a male preference for animal- and plantrelated activities only during teen age years and only in Sapporo. In contrast, respondent Keiko (39, female, from Sapporo) described playing with insects as one of the reasons why she used IGS:

"Finding bugs, playing in grass as high as the kids themselves - what a great experience for children! It certainly was for me. I found bugs that just weren't there in parks."

While male respondents in Sapporo were more likely to recall experiencing few if any problems using IGS as teenagers, no category of problems showed a significantly higher number of affected female respondents. Further research may be necessary to better understand what barriers teenage Japanese girls could be encountering. Generally however, differences in IGS use appear to be limited, suggesting IGS may play an important role for both boys and girls.

\section{Limitations}

This study has some limitations and methodological considerations. The relatively low response rate (Brisbane 6.4\%, Sapporo 8.2\%) reflects common difficulties with mailback studies (Veal 2011) and demands careful interpretation of the results to avoid overgeneralization. However, the sample is sufficient for the exploratory research undertaken in this paper. The respondents' age in this survey covered a large range. Consequently, the memories of two individuals may refer to different points in time, which may affect the study's accuracy (Jones 2003). As discussed above, "memory as methodology" means we need to be careful in interpreting findings and their implications (Jones 2013). Cross-cultural comparative research is commonly based on translations of research material such as questionnaires, which may influence the way the text is interpreted by respondents. To minimize such influence, the instrument used in this study was pilot tested and adjusted with the help of Japanese native speakers. Finally, while the respondents were urban residents, the study did not assess the extent to which their childhood landscape was urbanized. Respondents growing up in rural areas possibly used spaces similar to urban IGS yet still identified themselves as nonusers. 


\section{Conclusions}

This study examined adult urban residents' memories of using IGS as children and teenagers in Brisbane and Sapporo. The results showed IGS use was very common among respondents in both cities, and most frequent during childhood. IGS was used for a wide variety of activities. Proximity and distinctive characteristics of IGS were the main reasons underpinning its use. Over $74 \%$ of respondents did not experience any problems when using IGS as children or teenagers.

These results corroborate previous research suggesting that in the past, children and teenagers have used IGS for recreational purposes, especially where there are more opportunities for play than those offered by formal greenspace (e.g. parks). However, a declining availability of IGS (such as vacant lots), and increasing safety concerns by parents may be limiting opportunities available to young people today. This raises a number of questions for future research. How do parental restrictions affect children and teenagers' use of IGS? Under what circumstances would parents encourage access to and use of IGS? Does the quantity of IGS available for recreation change over time? Researchers could interview residents about past IGS use and accompany them on walks to retrace and map informal childhood landscapes, possibly with the help of old photographs (including aerial photography). GIS analysis could facilitate the reconstruction of past access and barriers to access.

Are attitudes towards IGS changing over time? Such shifts have been observed in environmental attitudes (Inglehart 1995) and in parental attitudes towards safety (see above). While IGS has received increasing attention from scholars (Rupprecht and Byrne 2014a), inter-generational research on urban residents' attitudes is scarce. Interviews with residents, and with professionals with long involvement in greenspace policy and planning could be compared with an analysis of policy and historical documents (e.g., newspapers, departmental annual reports) to examine how attitudes might have shifted.

What role can urban planning play in providing young people with access to IGS? How can planners and designers improve the design of formal greenspaces to provide some of the benefits of IGS (e.g. re-wilding some parks)? Research suggests the special characteristics of IGS (e.g., legal uncertainty, liability issues) pose a challenge for planners, and IGS users are often wary of loosing the freedom and absence of order these spaces provide (Campo 2013). As Cloke and Jones note, a 'culture of threatened 
litigation' $(2005,317)$ can make local authorities and land managers wary about wild, unkempt and disorderly spaces - lest they are sued for harm caused to children by physical objects, adults, or other children. Could resident-led informal management help to make IGS more accepted without losing its potential to provide what formal greenspaces cannot (Rupprecht et al., forthcoming)?

Finding answers to these questions could improve young people's opportunities for informal nature contact. Doing so could potentially benefit not only young people's mental and physical health, but also their interest in nature conservation. As Dunn and colleagues (2006) argue, global conservation efforts may depend on the interest people have in nature conservation, an interest they form largely through experiencing nature within the cities they live in. Could the IGS of today become the treasured urban spaces of tomorrow? History has taught us that disparaged urban spaces regularly become urban treasures when they are seen in fresh ways.

\section{Acknowledgements:}

The authors are deeply grateful to Yumi Nakagawa for invaluable help with data collection, the Japanese survey instrument and data entry, to Kumiko Nakagawa for assistance with the Japanese survey instrument and Japanese qualitative responses, to Dr Hirofumi Ueda for assistance with the Japanese survey instrument and data collection in Sapporo, to Dr Bill Metcalf for advice on research design, to two anonymous reviewers for their helpful comments and for pointing out vital literature, and to all respondents for participating in this study. 


\section{References}

Bell, Simon, Catharine Ward Thompson, and Penny Travlou. 2003. "Contested Views of Freedom and Control: Children, Teenagers and Urban Fringe Woodlands in Central Scotland." Urban Forestry \& Urban Greening 2 (2): 87-100.

Berg, Mary, and Elliot A Medrich. 1980. "Children in Four Neighborhoods: the Physical Environment and Its Effect on Play and Play Patterns." Environment and Behavior 12 (3): 320-48. doi:10.1177/0013916580123003.

Brisbane City Council. 2010. “City Plan 2000.” Brisbane.

Burgess, E W. 1916. "Juvenile Delinquency in a Small City." Journal of the American Institute of Criminal Law and Criminology 6 (5): 724. doi:10.2307/1133346.

Campo, Daniel. 2013. The Accidental Playground. New York: Fordham University Press.

Carr, Stephen, and Kevin Lynch. 1968. "Where Learning Happens.” Daedalus 97 (4). American Academy of Arts \& Sciences: 1277-91. doi:10.2307/20013424?ref=search-gateway:1 ec31b4efa5d1c1ce541275ce5b60fec.

Cheng, Judith Chen-Hsuan, and Martha C Monroe. 2012. "Connection to Nature: Children's Affective Attitude Toward Nature." Environment and Behavior 44 (1): 31-49.

Clements, Rhonda. 2004. "An Investigation of the Status of Outdoor Play." Contemporary Issues in Early Childhood 5 (1): 68-80.

Cloke, Paul, and Owain Jones. 2005. "'Unclaimed Territory': Childhood and Disordered Space(s)." Social \& Cultural Geography 6 (3): 311-33. doi:10.1080/14649360500111154.

Del Tredici, Peter. 2010. Wild Urban Plants of the Northeast: A Field Guide. Ithaca: Cornell University Press.

Donnelly, Dennis. 1980. "The Child in the Environment." Built Environment (1978-) 6 (1). Alexandrine Press: 62-67. doi:10.2307/23286086?ref=searchgateway:1ec31b4efa5d1c1ce541275ce5b60fec.

Dunn, Robert R, Michael C Gavin, Monica C Sanchez, and Jennifer N Solomon. 2006. "The Pigeon Paradox: Dependence of Global Conservation on Urban Nature." Conservation Biology 20 (6): 1814-16. doi:10.1111/j.1523-1739.2006.00533.x.

Edensor, Timothy J, Bethan Evans, Julian Holloway, Steve Millington, and Jon Binnie. 2012. "Playing in Industrial Ruins: Interrogating Teleological Understandings of Play in Spaces of Material Alterity and Low Surveillance." In Urban Wildscapes, edited by Anna Jorgensen and Richard Keenan, 65-79. Abingdon: Routledge.

Elsley, Susan. 2004. “Children's Experience of Public Space.” Children \& Society 18 
(2): 155-64. doi:10.1002/chi.822.

Field, Andy. 2009. Discovering Statistics Using SPSS. 3rd ed. London: SAGE.

Fukaya, Masashi. 1999. "Kodomotachi No Asobi." [Children's play.] Monografu: Shōgakusei Nau 19 (1). Benesse Educational Research Center. http://a111.g.akamai.net/f/111/143111/15m/benesse1.download.akamai.com/1431 11/j/monographpdf/1/1-vol-19-1.pdf

Gaster, S. 1991. "Urban Children's Access to Their Neighborhood: Changes Over Three Generations." Environment and Behavior 23 (1): 70-85. doi:10.1177/0013916591231004.

Gobster, Paul H. 2012. "Appreciating Urban Wildscapes." In Urban Wildscapes, edited by Anna Jorgensen and Richard Keenan, 33-48. Abingdon: Routledge.

Hartig, Terry, Richard Mitchell, Sjerp de Vries, and Howard Frumkin. 2014. "Nature and Health." Annual Review of Public Health 35 (1): 207-28. doi:10.1146/annurev-publhealth-032013-182443.

Hayashi, Masayuki, Yoritaka Tashiro, and Takeshi Kinoshita. 1999. "A Study on Vacant Lots Enclosed by Fences in Relation to Urbanization." Journal of the Japanese Institute of Landscape Architecture 63 (5): 667-70. doi:10.5632/jila.63.667.

Henniger, Michael L. 1994. "Adult Perceptions of Favorite Childhood Play Experiences." Early Child Development and Care 99 (1). Routledge: 23-30. doi:10.1080/0300443940990102.

Inglehart, Ronald. 1995. "Public Support for Environmental Protection: Objective Problems and Subjective Values in 43 Societies." PS: Political Science and Politics 28 (1): 57-72. doi:10.2307/420583.

Jones, Alasdair. 2013. "A Tripartite Conceptualisation of Urban Public Space as a Site for Play: Evidence From South Bank, London." Urban Geography 34 (8): $1144-70$.

Jones, Owain. 2003. "'Endlessly Revisited and Forever Gone': On Memory, Reverie and Emotional Imagination in Doing Children's Geographies. An 'Addendum' to "'To Go Back Up the Side Hill": Memories, Imaginations and Reveries of Childhood' by Chris Philo." Children's Geographies 1 (1): 25-36. doi:10.1080/14733280302185.

Jorgensen, Anna, and Richard Keenan, eds. 2012. Urban Wildscapes. Abingdon: Routledge.

Karsten, Lia. 2005. "It All Used to Be Better? Different Generations on Continuity and Change in Urban Children's Daily Use of Space." Children's Geographies 3 (3). Routledge : 275-90. doi:10.1080/14733280500352912.

Keniger, Lucy, Kevin Gaston, Katherine Irvine, and Richard Fuller. 2013. "What Are the Benefits of Interacting with Nature?" International Journal of Environmental 
Research and Public Health 10 (3): 913-35. doi:10.3390/ijerph10030913.

Larson, Reed W, and Suman Verma. 1999. "How Children and Adolescents Spend Time Across the World: Work, Play, and Developmental Opportunities.." Psychological Bulletin 125 (6): 701-36.

Laurent, Erick L. 2005. "Children,'Insects' and Play in Japan." Edited by A L Podberscek, E S Paul, and J A Serpell. Companion Animals and Us: Exploring Relationships Between People and Pets: 61-89. Cambridge: Cambridge University Press.

Lekies, Kristi S, and Thomas H Beery. 2013. "Everyone Needs a Rock: Collecting Items From Nature in Childhood." Children Youth and Environments 23 (3): 6668 .

Los Angeles Department of Playground and Recreation. 1938. Today's Leisure, City of Los Angeles. Los Angeles (California).

Louv, Richard. 2008. Last Child in the Woods: Saving Our Children From NatureDeficit Disorder. Chapel Hill: Algonquin Books.

Maller, Cecily Jane. 2009. "Promoting Children's Mental, Emotional and Social Health Through Contact with Nature: A Model." Health Education 109 (6): 52243. doi:10.1108/09654280911001185.

Moore, Robin C. 1986. Childhood's Domain: Play and Place in Child Development. London: Croom Helm.

Moore, Robin C. 1997. "The Need for Nature: A Childhood Right.” Social Justice 24 (3 (69): 203-20.

Mugford, Katy. 2012. "Nature, Nurture; Danger, Adventure; Junkyard, Paradise; The Role of Wildscapes in Children's Literature." In Urban Wildscapes, edited by Anna Jorgensen and Richard Keenan, 80-96. Abingdon: Routledge.

Nishino, Hitoshi J, and Reed Larson. 2003. “Japanese Adolescents' Free Time:Juku, Bukatsu, and Governmental Efforts to Create More Meaningful Leisure." New Directions for Child and Adolescent Development 2003 (99): 23-36. doi:10.1002/cd.64.

Nohl, Werner. 1990. "Gedankenskizze Einer Naturästhetik Der Stadt." [Thought sketch of an urban nature aesthetic] Landschaft Und Stadt 22 (2): 57-67.

Pearn, John. 2013. "A Tree House." Journal of Paediatrics and Child Health 49 (9): E361-64. doi:10.1111/jpc.12228.

Philo, Chris. 2003. “To Go Back Up the Side Hill': Memories, Imaginations and Reveries of Childhood." Children's Geographies 1 (1): 7-23. doi:10.1080/14733280302188.

Platt, Lorne. 2012. “Parks Are Dangerous and the Sidewalk Is Closer': Children's Use of Neighborhood Space in Milwaukee, Wisconsin." Children Youth and 
Environments 22 (2): 194-213.

Pyle, Robert Michael. 2002. "Eden in a Vacant Lot: Special Places, Species, and Kids in the Neighborhood of Life." In Children and Nature: Psychological, Sociocultural, and Ecolutionary Investigations, edited by Peter $\mathrm{H}$ Kahn and Stephen R Kellert, 305-27. Cambridge, MA: MIT Press.

Read, Jane. 2010. "Gutter to Garden: Historical Discourses of Risk in Interventions in Working Class Children's Street Play." Children \& Society 25 (6): 421-34. doi:10.1111/j.1099-0860.2010.00293.x.

Rupprecht, Christoph D D, and Jason A Byrne. 2014a. "Informal Urban Greenspace: A Typology and Trilingual Systematic Review of Its Role for Urban Residents and Trends in the Literature." Urban Forestry \& Urban Greening. doi:10.1016/j.ufug.2014.09.002.

Rupprecht, Christoph D D, and Jason Byrne. 2014b. "Informal Urban Green-Space: Comparison of Quantity and Characteristics in Brisbane, Australia and Sapporo, Japan.” PLoS ONE 9 (6): e99784. doi:10.1371/journal.pone.0099784.

Rupprecht, Christoph D D, Jason A Byrne, Hirofumi Ueda, and Alex Y H Lo. Forthcoming. "'It's Real, Not Fake like a Park': Residents' Perception and Use of Informal Urban Green-Space in Brisbane, Australia and Sapporo, Japan." Landscape and Urban Planning.

Sapporo Kankyōkyoku Midori No Suishinbu. 2011. "Sapporo Basic Green Plan." Sapporo.

Schneekloth, LH. 2007. "Unruly and Robust: an Abandoned Industrial River." In Loose Space: Possibility and Diversity in Urban Life, edited by Karen A Franck and Quentin Stevens, 253-70. Abingdon: Routledge.

Sproule, Warren. 2006. "Content Analysis." In Social Research Methods: An Australian Perspective, edited by Maggie Walter, 114-33. Oxford: Oxford University Press.

Strudler, Arielle, and Charles Schaefer. 1997. "Adults' Perceptions of Favorite Childhood Play Experiences: a Replication Study." Psychological Reports 81 (3): 1017-18.

Sugiyama, Takemi, and Catharine Ward Thompson. 2008. "Associations Between Characteristics of Neighbourhood Open Space and Older People's Walking." Urban Forestry \& Urban Greening 7 (1): 41-51. doi:10.1016/j.ufug.2007.12.002.

Tabata, Sadatoshi, and Jin-Seon Kim. 1989. "A Study on the Existing Pattern of Open Space and Composition of Greenery Space in High-Density Residential Districts." The Technical Bulletin of Faculty of Horticulture, Chiba University 42: 67-72.

Thomas, Angela. 2007. Youth Online: Identity and Literacy in the Digital Age. New York: Peter Lang.

Treacher, Amal. 2000. "Children: Memories, Fantasies and Narratives: From 
Dilemma to Complexity." In Memory and Methodology, edited by S Radstone, 133-53. New York: Berg Publishers.

United Nations, Department of Economic and Social Affairs, Population Division. 2012. "World Urbanization Prospects." New York: United Nations.

Valentine, Gill, and John McKendrick. 1997. "Children's Outdoor Play: Exploring Parental Concerns About Children's Safety and the Changing Nature of Childhood." Geoforum 28 (2): 219-35. doi:10.1016/S0016-7185(97)00010-9.

van der Burgt, Danielle. 2013. "Spatial Avoidance or Spatial Confidence? Young People's Agency in the Active Negotiation of Risk and Safety in Public Space." Children's Geographies: 1-15. doi:10.1080/14733285.2013.828455.

Veal, Tony A J. 2011. Research Methods for Leisure \& Tourism. Harlow: Financial Times Prentice Hall.

Ward, Colin. 1978. The Child in the City. New York: Pantheon Books.

Ward Thompson, Catharine. 2002. "Urban Open Space in the 21st Century." Landscape and Urban Planning 60: 59-72.

Ward Thompson, Catharine. 2012. "Places to Be Wild in Nature." In Urban Wildscapes, edited by Anna Jorgensen and Richard Keenan, 49-63. Abingdon: Routledge.

Ward Thompson, Catharine, Peter Aspinall, and Alicia Montarzino. 2007. "The Childhood Factor: Adult Visits to Green Places and the Significance of Childhood Experience." Environment and Behavior 40 (1): 111-43. doi:10.1177/0013916507300119.

Wolch, Jennifer, Michael Jerrett, Kim Reynolds, Rob McConnell, Roger Chang, Nicholas Dahmann, Kirby Brady, Frank Gilliland, Jason G Su, and Kiros Berhane. 2011. "Childhood Obesity and Proximity to Urban Parks and Recreational Resources: a Longitudinal Cohort Study." Health and Place 17 (1): 207-14. 